1. Texto escrito como uma crítica-ensaio do livro Do visível ao tangível: em

em bu

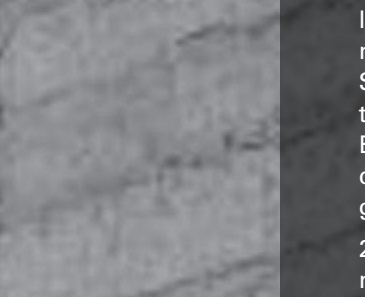

busca de um lugar pós-utopico e apresentado na mesa-redonda "A possibilidade de um lugar singular", ocorrida no dia 14 de abril de 2011, dentro do Seminário "A resistência do tátil. Leitura livre acerca do ensaio de Hygina Bruzzi Do visível ao tangível: em busca de um lugar pós-utópico", em homenagem à autora.

2. Graduado em Arquitetura e Urbanismo pela PUC Minas em 2000, com especialização pelo IEC/PUC Minas em "Arquitetura contemporânea: projeto e crítica" em 2001, mestre em Análise Crítica e Histórica da Arquitetura e Urbanismo pela Escola de Arquitetura da UFMG em 2005, doutor em Poéticas da Modernidade, pela Faculdade de Letras da UFMG, em 2012, professor do curso de Arquitetura e Urbanismo do Departamento de Arquitetura e Artes Aplicadas da UFSJ. 


\title{
ACERCA DAS RETICÊNCIAS: \\ UMA LEITURA LIVRE DO \\ LIVRO DO VISÍVEL AO \\ TANGÍVEL: EM BUSCA \\ DE UM LUGAR PÓS-UTÓPICO, \\ DE HYGINA BRUZZI'
}

ABOUT ELLIPSIS: A READING OF DO VISÍVEL AO TANGÍVEL:

EM BUSCA DE UM LUGAR PÓS-UTÓPICO, OF HYGINA BRUZZI

Frederico Canuto ${ }^{2}$

\begin{abstract}
Resumo
Este texto é uma leitura feita com base no livro Do visível ao tangível: em busca de um lugar pós-utópico, de Hygina Bruzzi, sendo apresentado em seminário em homenagem à autora. O objetivo é discutir os conceitos de medida e escala apresentados por ela nessa obra, atrelando-os ao conceito de singular, com base na leitura do livro do ensaísta português Herberto Helder, Os passos em volta, e da obra When faith moves mountains, do artista belga Francis Allys.
\end{abstract}

Palavras-chave: Escalas. Medidas. Singular.

\begin{abstract}
The present text was presented at the Seminar in honor of the Hygina Bruzzi and it is a reading from her book Do visível ao tangível: em busca de um lugar pós-utópico, of Hygina Bruzzi. Our intend is to discuss the concepts of measure and scale presented in this particular book through the concept of singular extracted from the book of Portuguese poet Herberto Helder, Os passos em volta, and work When faith moves mountains, of the Belgian artist Francis Allys.
\end{abstract}

Key words: Scale. Measure. Singular. 
Primeiramente, gostaria de agradecer a oportunidade de participar deste seminário. Creio que Hygina não poderia ganhar homenagem maior que uma leitura livre como esta de seu livro Do visível ao tangível: em busca de um lugar pós-utópico. A discussão das ideias, pensamentos e questões acerca do lugar ou da falta de lugar, assim como sua possibilidade singular, produz um ambiente para novos apontamentos e a rediscussão das mudanças no estado da arte da própria Arquitetura (inclusive nesta mesa), construindo afirmações, ainda que precárias ou iniciais.

E este texto é uma dívida minha para com ela. Apesar de não ter tido aulas com ela em minha graduação, como quase todos os outros membros deste seminário, tenho de reconhecer que recebi dela uma herança. Pensando sobre dívida e herança, lembro-me do modo como o filósofo franco-argelino Jacques Derrida trata o tema.

Segundo o autor, ao recebermos uma herança, dois movimentos são realizados. O primeiro é de aceitação total do que se está a receber. Não há escolha, mas apenas se recebe incondicionalmente o que está sendo dado. Logo após tal momento, temos a dívida para com quem nos fez a oferta: lê-lo criticamente, deixando para trás o que não tem serventia e partindo do que consideramos importante, de forma a construir um texto diverso. Indo e voltando sempre para nos servirmos do que foi deixado.

Assim, este é meu propósito: com base no livro de Hygina, escolher o que serve para escrever outro texto.

Logo na introdução do livro de Hygina, há uma discussão sobre a crise contemporânea do lugar, levando em consideração os novos meios de comunicação e seu impacto sobre a experiência do que a autora chama de "o peso próprio das coisas". Ou seja, sua preocupação, entre outras, gira em torno do modo como experiências virtuais, e "à velocidade da luz", influem em nossa percepção do tempo e do espaço. Como se fosse um momento de respiro no texto, para encerrar esta parte introdutória, ela coloca no final de um parágrafo: "Para mim o que define a arquitetura ainda é a medida e a escala..." (BRUZZI, 2001, p. 32).

No final dessa frase, não há ponto final. Apenas reticências. As noções de medida e escala ficam momentaneamente indefinidas, e é a partir dessa indefinição que quero prosseguir.

Normalmente associadas a valores de proporções exatas, matemáticas, como metros, centímetros, 1 para 500 ou para 1 000, medida e escala, desde a Arquitetura moderna e sua racionalização do mundo, são operadas como parâmetros de uma massificação. Pela desumanização da Arquitetura ao considerar a si mesma como jogo de encaixes para o estabelecimento de uma racionalidade construtiva, esses dois conceitos tornaram-se base de pensamento e produção de uma arquitetura cujos usuários nada mais são do que números. O corpo como medida e escala para a Arquitetura não seria um corpo que se move no espaço e em construção social com outros 
corpos, inclusive reativo ao espaço que habita, mas um com medidas próprias únicas e universais, estabelecidas dentro de tabelas e gráficos, independentes de contextos.

Ainda que haja uma preocupação em estender os padrões corpóreos para o desenho do espaço arquitetônico para além do modulor, cânone corbusiano, os conceitos de medida e escala na Arquitetura ainda sofrem do que parece ser uma esquizofrenia: o dever de ser local e global ao mesmo tempo. Essa medida básica corporal (tornada abstrata desde a Arquitetura moderna, associando o corpo que se move no espaço a especificidades como acessibilidade ou tamanho de aberturas de uma parede ou medida de espaços como o de dormir) tem um duplo dever: ser entendida como produto de um contexto específico e local, assim como universalmente reconhecida, a fim de se construir um novo padrão. Desse modo, essa nova padronização que surge de uma exceção diria de uma abertura a especificidades locais por parte dessa racionalidade global. Questões específicas e não colocadas dentro de legislações, como a preocupação com as questões ambientais ou o desenho universal, tornam-se mundialmente aceitas quando transformadas em leis (o que não é necessariamente acompanhado de um alargamento da sensibilidade estética relacionada a essas mesmas questões). Normalmente, quando leis, são tratadas como deveres acríticos e punitivos se não cumpridos.

Portanto é exatamente essa a limitação ou síndrome surgida nesta dialética local e global: a produção de um novo padrão. A nova medida perde o contexto e se torna lei que tudo abrange, fazendo inócua qualquer sensibilidade requerida daquele que projeta. Atingindo um domínio global, a Arquitetura se torna cada vez mais industrializada, mais racional, e atinge cada vez mais a vida urbana pela superficialização de toda imagem numa escala territorial medida em 1 para 100000 e por cartografismos ao alcance da mão pela rede mundial, como o Google Earth(o.

Por exemplo, pensemos a legislação relacionada aos cadeirantes. A questão do cadeirante e dos acessos, antes de sua NBR específica, dependia de uma sensibilidade estética e até mesmo ética do arquiteto e (ou) de qualquer projetista-construtor ao planejar espaços. Quando tal sensibilidade torna-se regra, em lei nesse caso, transforma-se em um dos operadores para controle do espaço projetado. Assim, ainda que tal lei traga avanços e espaços físicos melhores, o fato é que a sensibilidade corporal do arquiteto é substituída por uma instrumentalização da questão ergonométrica pelo corpo envolvendo esse tipo específico. Uma exceção se torna regra. O que antes era específico, torna-se universal. E a inteligência e a sensibilidade do arquiteto para se colocar e pensar com o outro são substituídas por uma apostila numérica, uma imagem perfeita e inabalável de como se move o cadeirante em todas as suas possibilidades.

Para possíveis especulações acerca das maneiras de se medir e de medir os outros e com os outros no espaço, o primeiro passo é escapar dessa dicotomia local-global. Assim, a reticência acerca de medidas e escalas, mencionada no título desta leitura do livro de Hygina, demanda a compreensão de 
que esses dois conceitos não são valores em si mesmos. Eles apontam para um outro, uma alteridade (sendo, assim, não inexatos e indeterminados, como a reticência poderia afirmar, mas referenciais). Dessa forma, para o argumento aqui proposto, esses dois conceitos, que normalmente são relacionados à exatidão das coisas em metros ou centímetros, podem ser pensados como dependentes de um referente. Numa relação cujas medidas estão em jogo é que conceitos se tornam operacionais para a Arquitetura. E é aí que se instala o singular como característica de um espaço de medidas construídas de modo compartilhado.

Assim, quero refletir sobre os conceitos de medida e escala em três níveis: primeiro, pensando o tipo de relação que eles são capazes de produzir; segundo, a natureza do lugar, ou não lugar, que é construído com base neles; terceiro e último, como o lugar singular pode vir a se tornar produção crítica de um jogo de referências com base nos conceitos de medida e escala.

Primeiramente, medir-se em Arquitetura relaciona-se não apenas com o tamanho ou peso das coisas, medido em centímetros ou quilos. Relaciona-se também com o uso que se faz do espaço diariamente. Medir-se num espaço é tarefa em que o corpo é unidade de medida, visto que estabelece relações de proximidade e distância. Porém o corpo não é um imóvel, estático e limitado. O corpo é base para construção de referências tendo em vista não somente o que ele faz funcionalmente, mas, principalmente, o que ele pode fazer no espaço. Desse modo, o corpo-referência para estabelecimento de valores é sempre base potencial de uma medida, nunca sendo estável ou exata. De modo contingencial, portanto, o corpo que habita o espaço arquitetônico poderá se expandir ou se retrair, dependendo do contexto em que está.

No espaço social e vivido, há uma especificidade próxima dessa potência crítica do corpo, esse corpo que pode. Medir o espaço de forma crítica significa também extrapolá-lo, fazendo dele usos para além de sua função. Se a função é o que normalmente se faz respeitando leis e padrões, para criar uma medida é necessário pensar contra o além do padrão como referência acrítica e imutável. Para mesurar limites, é preciso ir até eles e atravessá-los, porque é nesse atravessamento que uma nova referência é criada de forma crítica. Se a função de um espaço é determinação traçada num projeto em centímetros, segundo leis e padrões universais, usando-o ao limite, para além do que foi projetado num primeiro momento, é que ele deixa de ser um padrão.

Na cidade, então, há espaços em que as práticas vão ao limite das possibilidades dadas pela Arquitetura, extrapolando as funções para as quais foram desenhadas num primeiro momento. Atividades ditas informais (como o uso que os lavadores de carro fazem dos bueiros como espaço de depósito de seus materiais de trabalho, ou canteiros de árvores e flores em passeios, que acabam por se tornar bancos para o descanso) são apropriações, expõem o caráter extrapolativo do medir-se no espaço. Ao mesmo tempo, expandem referências espaciais até então tidas como invariáveis acerca do que é um banco, do que é um depósito a partir do uso. Mais ainda, criam novas 
referências, não apenas acerca do objeto usado para sentar, mas das maneiras de se sentar, guardar e outras atividades.

Uma inteligibilidade é construída entre o espaço e o corpo. E o que é gerado a partir daí é uma violência. Para além dos limites, atravessando padronizações de tamanho e comportamento, medir é incorporar ou colocar o corpo em questão pelo uso, atividade não apenas relacionada ao olhar e ao observar, para construir um parâmetro de medida. Violenta-se a Arquitetura para produzir nossas próprias medidas, inclusive comportamentais.

Sobre o lugar possível construído por essa inteligibilidade crítica, não podemos pensar em termos de fixidez, pois esse termo é sinônimo de padrão e imagem fixa. Pensar em termos de movimento de produção parece mais acertado, pois o espaço físico e o uso feito dele são interdependentes e variáveis no tempo, em acordo com as necessidades. Assim, o interesse deste argumento envolve a produção de um lugar e não o lugar em si, ou como os lugares são produzidos dialeticamente, pela rotina, funcionalidade cristalizada no corpo e seus movimentos, novos usos e apropriações.

Hygina, ao pensar o lugar que pode ser produzido por um conhecimento crítico, define-o como pós-utópico, afirmando que "se a utopia é o não lugar u-topos, ou eu-topos, lugar ideal ou imaginário, o lugar pós-utópico é o lugar do não lugar." O lugar do não lugar, à primeira vista, parece um paradoxo. Porém, ainda que reconheçamos essa categoria do não lugar como espacialidade onde o cinético (velocidade) substitui o sinestésico (tátil), anulando o corpo, caracterizando uma assepsia dos espaços, o termo pode abrir outras possibilidades de significado quando pensado com base na exceção e não na regra. Marc Augé, autor do livro Não lugares, vislumbra uma condição segundo a qual o não lugar aproxima-se do seu oposto: o lugar. Parafraseando o próprio Augé (2003, p. 74), “O não lugar como o lugar: aquele nunca existe sob uma forma pura; onde lugares se recompõem nele; onde relações se reconstituem nele".

Assim, o não lugar ganha outros matizes baseados nessa sua ambivalência. Ganha contornos não de um espaço que é, mas daquele que é produzido por relações. Vejamos, então: no momento em que distâncias são cada vez menores por meio do uso de gadgets eletrônicos e o espaço doméstico é permeável a fluxos de informação que requisitam um reposicionamento do nosso corpo em relação aos diferentes espaços que recortam nossa experiência, esse não lugar como espaço de reconstituição de referencias é permissivo, então, pelo raciocínio do antropólogo, ao estabelecimento de novas inteligibilidades, novas escalas e medidas. Interessa pontuar que o espaço como não lugar estabeleceria assim novas relações, produzindo novos lugares de troca, novas sociabilidades no espaço. Logo, produziria novos dimensionamentos relacionais a públicos espaciais, em que a Arquitetura é um plano no qual medidas e escalas são produzidas por interceptações e cruzamentos de informação. O não lugar como lugar da contemporaneidade o é, dessa maneira, porque, a partir dele, são atravessadas e produzidas novas referências inteligíveis entre um eu e o mundo, que aqui é alteridade. 
Pensando nos espaços e nas relações sociais que estabelecemos com eles, e a partir deles, o não lugar como negativo do lugar então não é o shopping center ou o aeroporto apenas, mas o tipo de relação de medida e escala sem qualquer tipo de construção referencial crítica que se estabelece entre nós e esses espaços. Ou seja, o aeroporto é asséptico não apenas porque instintivamente todos os aeroportos do mundo parecem iguais, mas também devido ao uso que se faz dele, caracterizado pela criação de padrões de comportamento e do que é socialmente aceito como normal pelo programa. O aeroporto é imagem do não lugar devido à repetição, e não à proposição, das sempre iguais relações sociais em espaços coletivos com um único fim: a reprodução dessas mesmas relações de produção sociais do espaço. Mas pode ser também não lugar, cuja identidade esvaziada apontaria para novas referências.

Se o movimento de produção desse lugar, ou não lugar, é o que está em causa, o espaço produzido não pode ser um novo padrão arquitetônico. Ele deve ser singular.

O conceito de singular é amplamente utilizado na crítica política atual e tal uso vem desde os anos 80, quando autores e críticos literários franceses como Jean-Luc Nancy e Maurice Blanchot usaram o termo para especificar um tipo de relação entre um e outro. Em Nancy, por exemplo, esse termo surge em Le communauté désoeuvreé e serve para caracterizar uma relação de linguagem entre o que se diz e sobre o que se diz caracterizada por uma inclinação (clinamen) em direção a uma não equivalência dos termos. O conceito, assim, define uma relação em que um não se refere a outro igual a si mesmo, mas um outro diverso de si mesmo, uma alteridade, como experimentação autônoma em termos de linguagem. Já para Blanchot, em La communauté inavouable, o singular aponta para uma relação amorosa, na qual o amor é relação direcionada ao desconhecido, abertura total.

Atualmente, o conceito singular reaparece na obra do filósofo Giorgio Agamben, La comunità che viene, para definir o ser que deseja, nas palavras dele, o "ser qual-quer". Ainda que esta obra, misto de manifesto filosófico e experimentação literária, não toque explicitamente questões espaciais como as aqui tratadas, o conceito de singular tratado pelo pensador italiano traz uma noção espacial central: limite. Para ele, o singular não é a definição de uma especificidade, mas de um limite do que é específico e surgido numa situação contingencial. Ou seja, não é um padrão, mas justamente o limite do que não está no padrão.

Seja no Direito ou na Filosofia, o que o singular coloca em questão é uma despersonalização, devendo ser compreendido como algo único desde sua especificidade e sua diferença em relação a qualquer imagem universalizante, global ou local, que porventura possa existir anteriormente. Portanto, pensar o diferente em sua diferença, sem qualquer imagem preexistente, é para o que o conceito de singular aponta. Se não atende a essa racionalidade que pretende abarcar todo o mundo ou fatias padronizadas dele, o singular é justamente a exceção ou o intempestivo (aquilo que não é iluminado, mas obscurecido por sua própria especificidade e unicidade). É definido 
pelo limite do que não se conhece. Assim, numa visão agambeniana, é sem referente anterior. Por isso, o filósofo italiano dirá que ele é exemplar em sua exemplaridade, pois sua única referência é ele mesmo.

Transferindo-se para nossa discussão aqui sobre o espaço, o singular relacionar-se-ia ao produzir um espaço cuja imagem é indiferente a qualquer padrão (nem contra ou a favor, muito menos passivo, mas indiferente, porque fora do jogo padronização-despadronização). Anulando esse jogo binário, o que pode o singular está estritamente relacionado a um ínterim entre o modo como um espaço é usado funcionalmente (padrão) e como ele está sendo usado criticamente (despadronização): esse espaço que está num tempo do "ainda não". Assim, possibilidade e singularidade tornam-se sinônimos porque são negação do que se é, mas ainda não se confirmam como um outro.

Trago à discussão agora Os passos em volta, livro escrito na década de 1960 pelo poeta português Herberto Helder. Em seu único livro de prosa, que críticos chamam de conjunto de 23 lugares-poema, esse escritor, penso, problematiza e, mais importante, constrói imagens desses lugares singulares, questão de nossa leitura aqui, para além das ambivalências local-global, lugar e não lugar.

$\mathrm{Na}$ chamada Antuérpia, espaço narrativo central para o conto "Os comboios que vão para Antuérpia", todos esses pares se desfazem. Nesse conto sobre um passageiro à espera de um transporte para a cidade, escalas e referências são (des)construídas, expandidas e violentadas, como dito anteriormente, em prol de novos regimes de inteligibilidade.

Ao lermos tal conto, um dos lugares-poema do livro, o nome da cidade não nos diz muito. Seu nome não significa nada como medida ou referência geográfica espacial para se construir na mente uma imagem urbana. Apesar de, na primeira frase, Antuérpia ser o local onde o narrador do conto está instalado, nos subúrbios dessa cidade belga, conforme a leitura avança e esse lugar retorna em outros contos do mesmo livro, Antuérpia torna-se "o lugar que não era"; "uma inspiração confusa e difusa"; "cidade igual a todas as outras", quando não é descrita apenas pelo que acontece lá ou até mesmo dentro de seus espaços privados. Como ele mesmo diz: "o que importa eram os comboios, que faziam estremecer o meu quarto" (HELDER, 2005, p. 39), este instalado numa casa sobre a linha férrea. Não vemos panoramicamente a cidade. Só é possível experimentá-la, e assim medi-la, por fragmentos dados nas imagens escritas, que mesmo assim são arreferenciais, pois genéricas: casa, escada, rua.

Daí, sua referência, seu chamado Deus, não é a cidade ou a figura religiosa a Ele comumente associada na cultura ocidental. É um comboio de destino indefinido, pois Antuérpia não é sítio final, mas ponto de partida. Em Antuérpia, o narrador-poeta sabe que "há prostitutas, há um calor humano degradado, a embriaguez. E lá também se morre" (HELDER, 2005, p. 40). Mas ainda mais importante para a localização indiferente da cidade é o mar, sinônimo, na cultura portuguesa, litorânea, 
do infinito, do desconhecido, do a perder de vista. O mar, escala de um perder de vista, é para onde se vai, onde se perde, onde se toca, de acordo com suas palavras, a loucura do mundo, onde Antuérpia ou qualquer outro nome que não faz sentido nenhum.

Quando, com base em uma analogia, o autor compara o comboio a um pensamento, o primeiro, veículo de passagem, torna-se parâmetro de medida do que se denomina uma "viagem sem fé, inconsequente, feita com o inexplicável ardor de quem se inicia na eternidade" (HELDER, 2005, p. 42). Assim, o lugar é o comboio como pensamento que leva para além de marcações históricas e geográficas, a produção de um próprio lugar por convergência. Logo, é um não lugar em constante produção, pois está sendo pensado na literatura de Helder: "Estou possuído pelos dons infernais com que se cria um estilo sem tempo, nem lugar, a fraternidade solitária, o amor sempre em viagem" (HELDER, 2005, p. 42).

Dessa maneira, não se tem a cidade, nem a vida rotineira local, mas, indiferentemente, as duas: partir sempre em frente. Ou, nas palavras de Helder, o princípio da metamorfose das formas.

$\mathrm{O}$ argumento sobre o espaço singular é dado, então, com base nessa leitura de Helder, não pelo fazer da obra, mas pelo que conserva no local: uma arquitetura constituída de deslocamentos e fugas de qualquer referência, pelo amor ou pela vontade. Mais ainda, pelo desligamento de qualquer referencial que Antuérpia possa estabelecer. Na implicação que esse espaço irá requerer, esse partir produz singularidade pela não interseção precisa entre a escala de centímetros ou metros dos moradores e de quilômetros de uma cidade. Indiferente aos dois, o desvio pede outras unidades de medição e uma arquitetura que desrespeita tanto a representação técnica e cartográfica padrão quanto a própria história dos moradores ou do local.

Entretanto, um deslocamento de referências se deu, ainda que uma nova não tenha sido escrita.

Continuando essa leitura de uma dimensão espacial do singular, o artista belga Francis Allys traz uma importante contribuição para associarmos a Helder.

Em seu vídeo feito em Lima, Peru, em 2002, denominado Quando a fé move montanhas (When faith moves mountains), o artista aposta nessa singularidade numa dimensão política que não é nem local, nem global, sendo associada ao desejo de produzir um outro discurso no espaço. Ao contratar centenas de trabalhadores peruanos para, num dia e hora marcados, munidos de uma pá, escavarem a areia de uma montanha e deslocarem-na de lugar, tem-se supostamente a alteração de coordenadas geográficas, histórias das pessoas com o referente, eixos visuais até então imóveis. Reconstrói-se uma paisagem, redesenha-se a natureza, realiza-se Arquitetura em dois registros indissociáveis: o pictórico e o tectônico.

No caso pictórico, ao mudar a montanha de lugar por alguns metros, o que Allys intercepta e distorce são as medidas e referências convencionais por meio de uma anulação de precisão e objetividade pragmática dos dispositivos cartográficos domésticos, porque já íntimos de nós, como o Google Ear- 
th@. O mapa ou imagem cartográfica que aparece na tela do computador mostra a montanha no mesmo lugar, embora ela não esteja mais lá. O que aparece na tela é um traço de um apagamento. Ou seja, um resto de movimento, algo como um espasmo; um mover-se permanecendo no mesmo lugar: uma marca invisível. Ou seja, é singular aqui porque a imagem produzida pela intervenção anula a dimensão global e a racionalidade a ela vinculada. O que se apresenta globalmente não condiz com o que há no local.

Do ponto de vista tectônico, o artista instala, na realidade social e física da cidade, um desvio. Um desvio de alguns centímetros que, mediante novas rotinas e histórias surgidas com esse trabalho, será absorvido pela cultura local. Uma mudança geográfica ínfima que destrói a relação histórica com o lugar já existente.

Assim, aquilo que não aparece no espaço produzido pelo olhar racional progressista que cobre tudo, nem para os moradores que ali vivem, configura-se nesse singular.

Uma arquitetura constituída de areia deslocada alguns centímetros de sua origem é o que fica. O singular não está no fazer da obra pelos que receberam por isso, mas pela implicação que ela irá requerer, tanto em nível pictórico quanto tectônico, dos moradores e suas novas histórias, e do próprio satélite; ou seja, quanto a medidas e escalas obtidas entre moradores, satélites e um monte de terra, esse desvio produz uma singularidade pela não interseção precisa entre a escala de centímetros ou metros dos moradores e de quilômetros de um satélite. Indiferente aos dois, o desvio pede outras unidades de medição e uma arquitetura que desrespeita tanto a representação técnica quanto a própria história dos moradores. Um medir o que não está visível. Uma tangibilidade que se dá no não lugar que é lugar: o vazio que é traço do apagamento. Um vazio que aponta para novas possibilidades.

A areia da montanha em Allys e o mar de Helder apontam para uma infinitude de possibilidades de corpos que não mais estão lá, mas que podem construir novas medidas e escalas.

\section{Ínterim ou fronteira}

Os dois (Helder e Allys) afirmam em sua poética um traço fulcral para se compreender medida e escala como movimentos de medição constantes: sua afirmação contemporânea.

Agamben, em "O que é o contemporâneo", afirma o contemporâneo não como o atual, não baseando sua formulação em uma questão temporal, portanto. O contemporâneo para ele relaciona-se ao obscuro, ou ao que não foi cooptado pela iluminação, pela racionalidade, que tudo instrumentaliza pelo distanciamento entre corpos.

Helder e Allys, em suas obras, afirmam justamente tal contemporaneidade ao desligarem medida e escala como bases estáveis de entendimento. O não lugar é pensado na mesma direção como o que abala o lugar. Nessa procura intensa, dada pela transgressão dos autores de padrões formalizados 
de compreensão do mundo (pela cartografia literária, que é a língua, e pela artística, o que, nesse caso, é representado por instrumentos medidores), tais conceitos ficam indiferentes ou são disfuncionais, pois não ajudam a produzir uma localização. Por isso, penso que Hygina termina com reticências sua frase "Para mim, a arquitetura ainda é sobre medidas e escalas...", porque percebe que defini-la é fazer e estabilizar justamente o que deve ser instável. As reticências deixam inoperantes tais conceitos: não se trata da negação do que há nem da afirmação de outro, mas de uma recusa de definição. Numa abordagem literária, seu gesto linguístico e gramatical é similar ao de Helder, pois ambos se recusam a fechar o pensamento em definições estáveis e limitadoras, recusam-se a realizar a obra, afirmando uma obscuridade como possibilidade, potência do "ainda não" definitivo: o mais atual possível é aquele que ainda está por vir.

\section{Referências}

AGAMBEN, Giorgio. A comunidade que vem. Tradução Antonio Guerreiro. Lisboa: Presença, 1993.

AUGÉ, Marc. Não lugares: introdução a uma antropologia da supermodernidade. Tradução Maria Lúcia Pereira. Campinas: Papirus, 2003.

BLANCHOT, Maurice. La comunidad inconfesable. Tradução Isidro Herrera. Madrid: Arena Libros, 2002.

BRUZZI, Hygina. Do visível ao tangível: em busca de um lugar pós-utópico. Belo Horizonte: C/Arte, 2001.

HELDER, Herberto. Doze nós numa corda: poemas mudados para o português. Lisboa: Assírio \& Alvim, 1997.

HELDER, Herberto. Passos em volta. Rio de Janeiro: Azougue, 2005.

HELDER, Herberto. Ouolof: poemas mudados para o português. Lisboa: Assírio \& Alvim, 1997.

NANCY, Jean Luc. La comunidad desobrada. Tradução Pablo Perera. Madrid: Arena Libros, 2006.

\section{Endereço para correspondência}

Frederico Canuto

Rua Angustura 228/1B - Bairro Serra

CEP 30220-290

Belo Horizonte/ MG

fredcanuto@gmail.com 